\title{
Comparative morphological evaluation of animal corneal parameters
}

\author{
VIDA BABRAUSKIENĖ, JUDITA ŽYMANTIENĖ, ALBINA ANIULIENE்*, \\ VIDA JUOZAITIENE்**, SNIEGUOLE் MALAKAUSKIENE், J. INGRIDA ALIONIENE்
}

\begin{abstract}
Department of Anatomy and Physiology, *Department of Veterinary Pathobiology, Faculty of Veterinary Medicine;
**Department of Animal Breeding and Nutrition, Faculty of Animal Husbandry Technology, Lithuanian University of Health Sciences, Kaunas, Tilžès 18, Kaunas, Lithuania
\end{abstract}

\section{Babrauskienẻ V., Žymantienè J., Aniulienẻ A., Juozaitienẻ V., Malakauskienẻ S., Alionienè J. I. Comparative morphological evaluation of animal corneal parameters \\ Summary}

The purpose of this study was to broaden the basic knowledge of corneal morphological structures in pigs, cows and rabbits and to find morphological and histological differences in the constituent corneal structures. After slaughter, corneal samples of 24 animals, including cows, pigs and rabbits, were investigated. Forty-eight eyeballs $(n=48)$ of 8 pigs, 8 cows and 8 rabbits were used for this study. Central corneal thickness (CCT) values in cows were higher than those in pigs $(\mathrm{P}<0.001)$ and rabbits. In rabbits, CCT, as a percentage of the eye axis length, was $55.03 \%$ greater than in cows and $40.55 \%$ greater than in pigs $(P<0.001)$. The thickness of substantia propria (stroma) depended on the species and accounted for more than $80 \%$ of the thickness of all layers of the cornea. The thickness of the anterior epithelium amounted to $15.81 \%$ of the thickness of all layers of the cornea in cows, $11.79 \%$ in pigs, and $8.48 \%$ in rabbits $(P<0.001)$. The data analysis showed that the caudal limiting membrane + endothelium was the thinnest layer of the cornea, with thickness ranging from $\mathbf{0 . 8 8 \%}$ to $2.40 \%$ of the total thickness of all layers of the cornea in the three species under study (P $<0.001)$. A statistically significant negative correlation was determined between the anterior epithelium and substantia propria in corneas of cows, pigs and rabbits $(\mathrm{P}<\mathbf{0 . 0 0 1})$. This paper describes the morphometric parameters of the cornea in pigs, cows and rabbits. These parameters will be of use to scientists using animal models in vision science research.

Keywords: pig, cow, rabbit, eye, cornea structures

The cornea is the front part of the eyeball and the transparent anterior segment of the globe of the eye that refracts light onto the retina. It is the first element in the eye's optical system, contributing $2 / 3^{\text {rd }}$ of the eye's total focusing power, and must remain essentially clear for optimal vision to be achieved. The cornea is also the most sensitive tissue in the body (4). The cornea consists of five basic layers: the epithelium, Bowman's layer, the stroma, Descemet's membrane (caudal limiting membrane) and the endothelium $(8,7)$. Hayashi et al. (9) present comparative observations on corneas, with special reference to Bowman's layer and Descemet's membrane in mammals and amphibians. According to Nautschel (14), there is disagreement about the existence of Bowman's layer in domestic animals. The structure of the stroma varies significantly between humans and animal species, such as cows, pigs, and rats (11). The cornea covers up to $30 \%$ of the rabbit eye. Due to its large size, the cornea is prone to trauma or other damages, including drying-out. The cornea, or the transparent front part of the eye, is a thin dense fibre-like structure characterized by 4 distinctive layers in rabbits: a keratinized layer of the epithelium (30 to $40 \mu \mathrm{m}$ ); the stroma formed by parallel bundles of collagen; Descemet's membrane ( 7 to $8 \mu \mathrm{m}$ ); and a single layer of the endothelium, which is rich in $\mathrm{Na}^{+}$-ATPase pumps (3). The eyes of animals are frequently used in (animal and human) vision science studies, in pharmacodynamic studies of ophthalmic drugs, as well as in healing and surgery of traumatic eye injury $(4,5,19,20)$.

Ocular diseases in food-producing animals play a significant role in economic losses (15). A large body of knowledge of corneal structures and functions is acquired from studying laboratory rodents, which are used as animal models for human research (17). However, the knowledge of corneal parameters in the pig, the cow and the rabbit is limited. 
Only a few investigations of the corneal comparative morphology of domestic animals have been published. Meridano et al. (13) and Nautschel et al. (14) measured the thickness of the corneal epithelium at different corneal loci in pigs, cows and other species of domestic animals.

Brunette et al. (6) conducted experiments to compare the pig and feline models for full thickness corneal transplantation. The eye of the domestic pig (Sus scrofa domestica) is an ex vivo animal model often used in vision science research (retina studies, glaucoma, cataracts, etc.). However, only a few papers provide anatomical descriptions of the pig's eye $(18,19)$. Damage and ulceration of the cornea are painful, as the surface of the cornea is well innervated.

Rabbit eyes have been widely used for ophthalmic research, as the animal is easy to handle and economical, compared to other mammals, and the size of a rabbit's eye is similar to that of a human eye. Rabbit eyes can be a good model for pharmacokinetic studies of intraocular drugs (1).

In pigs, corneal diameter and thickness are greater than they are in humans. Moreover, pig cornea is suitable for xenocorneal transplantation using the same preservation protocol as that for human cornea with respect to biophysical and functional properties, and it can be stored for up to 7 days for transplantation in human clinical trials. An age limitation of donor pigs may be required for qualified corneal products to be used in human trials (10).

Our study will be of interest to researchers studying comparative ophthalmology in veterinary medicine, as well as to those who design drug therapies for animals. In the literature, there are no data about the morphological features of the eyes of Lithuanian black and white cows and Lithuanian white pigs.

The purpose of this study was to broaden the basic knowledge of corneal morphological structures in pigs, cows and rabbits, and to find morphological and histological differences in the constituent corneal structures.

\section{Material and methods}

Eyeballs and corneal samples from 24 healthy animals (cows, pigs and rabbits) were used in the study, including forty-eight eyeballs of 8 healthy pigs, 8 cows and 8 rabbits. All animals were free from ocular diseases. The study was conducted on Lithuanian black and white cows aged 16-18 months, Lithuanian white pigs aged 6 months and white rabbits aged 12 months. All animals were females. Immediately after slaughter, both eyeballs were enucleated. The central corneal thickness (CCT) and the length of the eye axis of the animals were measured using an A-type ultrasonographic pachymeter DGH 500 (Pachette $\left.{ }^{\mathrm{TM}}\right)$. After measurement of these parameters, the cornea was taken for histological examination and light microscopy. The following technique of light microscopy was applied: $5 \times 5 \mathrm{~mm}$ sections of the corneas were fixed in Buen's solution for 24 hours, dehydrated in a series of ethanol solutions $(50 \%$,
$70 \%, 80 \%, 100 \%$ ), and embedded in paraffin. The sections $(4 \mu \mathrm{m})$ were stained with hematoxylin-eosin. The slides were examined under a light microscope (Olympus, Tokyo, Japan) at $\times 400$ magnification, and image analysis was carried out by means of an Olympus BX43 light microscope and the image analysis program Olympus Stream Essentials version 1.9.1 (Olympus, Tokyo, Japan).

Statistical analysis. Descriptive statistics (mean \pm standard error) and Pearson's correlation were calculated using the R 2.1.0 package (http://www.r-project.org/). T-test was used to detect significant differences between the groups (the results were considered significant at $\mathrm{P} \leq 0.05$ ).

\section{Results and discussion}

This study describes the corneal parameters of cows, pigs, and rabbits determined by ultrasonic pachymetry and histomorphometrical methods. CCT values showed statistical difference $(\mathrm{P}<0.001)$ between cows and pigs: CCT was greater in cows. Nautschel et al. (14) discovered that CCT was greater in cows $(283.5 \pm 16.6$ $\mu \mathrm{m})$ than it was in pigs $(184 \pm 19.8 \mu \mathrm{m})$. Scientists suppose that corneal thickness is related to the habitat of a given species $(2,12,14)$. The corneal epithelium provides a protective interface with the environment. Ruminants and camels living in open grasslands are more likely to be exposed to rough environmental conditions than other animals (e.g. camels in a hot and dry climate); However, this hypothesis has not been scientifically confirmed (14).

In the present study the cornea of pigs was the thinnest as compared with that of other animals. The CCT obtained for pigs in our investigation was similar to that obtained by other researchers. Sanchez et al. (19) measured corneal parameters in five enucleated eyes of pigs aged 6-8 months and determined that central corneal ultrasound pachymetry of pigs was $877.6 \pm 13.58 \mu \mathrm{m}$ (CI 95\% $865.70 \mu \mathrm{m}-889.50 \mu \mathrm{m}$ ).

Rabbits have been increasingly used as an experimental animal model. The CCT of white rabbits in our study was $1.13 \pm 0.09 \mathrm{~mm}$, whereas Wang et al. (21) found a statistical difference between CTT values in pigmented and white rabbits $(390 \pm 14.2$ and 373 $\pm 7.2 \mu \mathrm{m}$ ). This fact is important for future studies. The length of the eye axis was greatest in cows. Differences between cows, pigs and rabbits were statistically significant $(\mathrm{P}<0.001)$. The corneal thickness as a percentage of the length of the eye axis for the three species of animals is presented in Tab 1. In rabbits, CCT as

Tab. 1. Descriptive statistics for cornea and length of eye axis

\begin{tabular}{|l|c|c|c|}
\hline Species & $\begin{array}{c}\text { CCT } \\
(\mathrm{mm})\end{array}$ & $\begin{array}{c}\text { Length of eye axis } \\
(\mathrm{mm})\end{array}$ & $\begin{array}{c}\text { CCT as percentage } \\
\text { of eye axis length } \\
(\%)\end{array}$ \\
\hline Cow & $1.29 \pm 0.03^{\mathrm{a}}$ & $32.38 \pm 0.37^{\mathrm{a}}$ & $3.98 \pm 0.11^{\mathrm{a}}$ \\
\hline Pig & $1.10 \pm 0.00^{\mathrm{b}}$ & $25.13 \pm 0.41^{\mathrm{b}}$ & $4.39 \pm 0.07^{\mathrm{b}}$ \\
Rabbit & $1.13 \pm 0.09$ & $18.48 \pm 0.47^{\mathrm{c}}$ & $6.17 \pm 0.56^{\mathrm{c}}$ \\
\hline
\end{tabular}

Explanations: $a, b, c-$ means with different superscript letters differ significantly at $\mathrm{P} \leq 0.001$ 
a percentage of the eye axis length was $55.03 \%$ greater than in cows and $40.55 \%$ greater than in pigs $(\mathrm{P}<0.001)$.

Histomorphometrical studies of the cornea showed that substantia propria (stroma) constituted the thickest of all corneal layers in all three species. The thickness of substantia propria depended on the animal's species and accounted for more than $80 \%$ of the thickness of all layers of the cornea (Tab. 2). According Tab. 2. Thickness of corneal layers

\begin{tabular}{|l|c|c|c|c|}
\hline Species & $\begin{array}{c}\text { Anterior } \\
\text { epithelium } \\
(\mu \mathrm{m})\end{array}$ & $\begin{array}{c}\text { Substantia propria } \\
(\text { stroma }) \\
(\mu \mathrm{m})\end{array}$ & $\begin{array}{c}\text { Caudal limiting } \\
\text { membrane } \\
+ \text { endothelium } \\
(\mu \mathrm{m})\end{array}$ & $\begin{array}{c}\text { All layers } \\
\text { of cornea } \\
(\mu \mathrm{m})\end{array}$ \\
\hline Cow & $70.00 \pm 0.70^{\mathrm{a}}$ & $362.00 \pm 8.62^{\mathrm{a}}$ & $10.63 \pm 0.56^{\mathrm{a}}$ & $442.63 \pm 8.28^{\mathrm{a}}$ \\
\hline Pig & $40.19 \pm 1.97^{\mathrm{b}}$ & $296.44 \pm 3.10^{\mathrm{b}}$ & $4.39 \pm 0.28^{\mathrm{b}}$ & $341.01 \pm 2.61^{\mathrm{b}}$ \\
Rabbit & $13.11 \pm 0.36^{\mathrm{c}}$ & $140.13 \pm 6.33^{\mathrm{c}}$ & $1.36 \pm 0.05^{\mathrm{c}}$ & $154.60 \pm 6.56^{\mathrm{c}}$ \\
\hline
\end{tabular}

Explanations: $\mathrm{a}, \mathrm{b}, \mathrm{c}-$ means with different superscript letters differ significantly at $\mathrm{P} \leq 0.001$ to Nautschel et al. (14), the corneal stroma is clearly the thickest corneal layer in animals, and it is composed of a uniform collagen fibril matrix that contains keratocytes arranged in an elongated, flattened manner. In the murine, porcine and bovine corneas, the stroma shows interwoven collagen patterns (11). The thickness of the anterior epithelium amounted to $15.81 \%$ of the thickness of all layers of the cornea in cows, $11.79 \%$ in pigs and $8.48 \%$ in rabbits $(\mathrm{P}<0.001)$ (Fig. 1). These differences can be explained by a significant variation in the number of cell layers in the corneal epithelium of different animal species. The bovine epithelium consisted of 11-15 cell rows, whereas in pigs there were only 8-12 rows of squamous cells (14).

The analysis of the total thickness of the caudal limiting membrane + endothelium indicated that this was the finest layer, accounting for $1.36 \pm 0.05 \mu \mathrm{m}$ or $0.89 \%$ (Tab. 2, Fig. 1) of the all layers of cornea in the three species $(\mathrm{P}<0.001)$. The same results were obtained by other researchers. The data analysis showed that the thickness of the anterior epithelium, substantia propria, and the caudal limiting membrane + endothelium varied greatly between the species (Fig. 1).

The thickness of the anterior epithelium amounted to $15.81 \%$ of the thickness of all layers of the cornea in cows, $11.79 \%$ in pigs and $8.48 \%$ in rabbits (Tab. 2). Thus, as a percentage of the total thickness of all corneal layers, the anterior epithelium in cows was $34.61 \%$ thicker than that in pigs and $85.83 \%$ thicker than that in rabbits. As a percentage of the total thickness of all corneal layers, the substantia propria in cows was $9.76 \%$ thinner than that in rabbits and $5.97 \%$ thinner than that in pigs. The substantia propria layer in cows was $8.84 \%$ thinner than that in rabbits and $5.19 \%$ thinner than that in pigs $(\mathrm{P}<0.001)$.

A statistically significant negative correlation was established between the anterior epithelium and substantia propria in cow, pig and rabbit corneas $(\mathrm{P}<0.001)$, and it was the same for all animal species tested (Tab. 3).

A negative relationship was established between the anterior epithelium and the caudal limiting membrane + endothelium in the pig cornea $(\mathrm{P}<0.05)$, and a statistically negative correlation was found between the substantia propria and the caudal limiting membrane + endothelium in the rabbit cornea $(\mathrm{P}<0.05)$. The correlation between the anterior epithelium and the

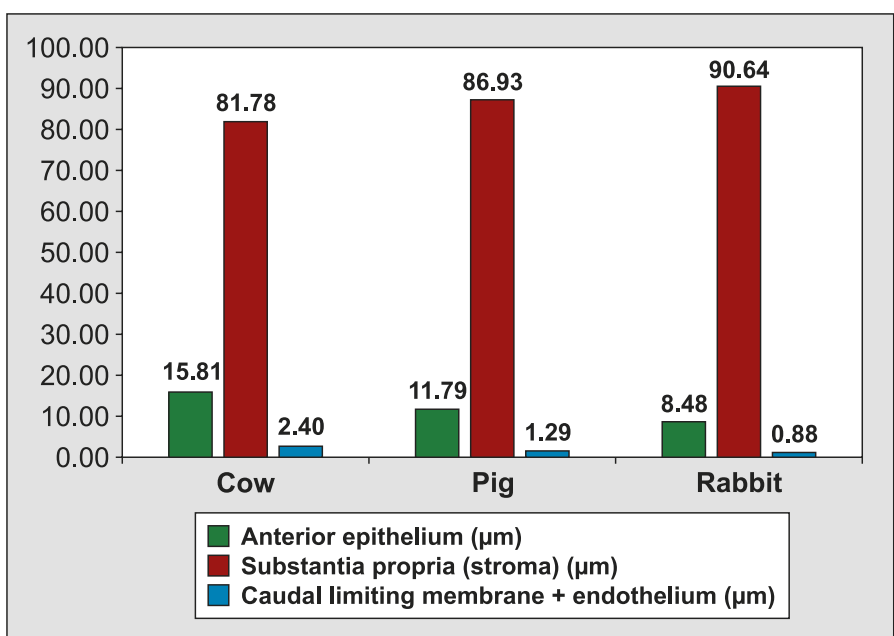

Fig. 1. Proportions of corneal layers in cows, pigs and rabbits

Tab. 3. Correlations between corneal layers in cows, pigs and rabbits

\begin{tabular}{|l|c|c|c|}
\hline Species & $\begin{array}{c}\text { Anterior epithelium } \\
\text { - substantia propria }\end{array}$ & $\begin{array}{c}\text { Anterior epithelium } \\
\text { - caudal limiting } \\
\text { membrane } \\
\text { + endothelium }\end{array}$ & $\begin{array}{c}\text { Substantia propria } \\
\text { - caudal limiting } \\
\text { membrane } \\
\text { + endothelium }\end{array}$ \\
\hline Cow & $-0.967^{* * *}$ & -0.054 & -0.203 \\
Pig & $-0.995^{* * *}$ & $-0.735^{*}$ & 0.664 \\
Rabbit & $-0.991^{* * *}$ & 0.588 & $-0.691^{*}$ \\
\hline
\end{tabular}

Explanations: * significant at $\mathrm{P} \leq 0.05, * * *$ significant at $\mathrm{P} \leq 0.001$

substantia propria was strongly negative. The relationship between the anterior epithelium and the caudal limiting membrane + endothelium varied from highly negative for pigs to highly positive for rabbits. The correlation between the substantia propria and the caudal limiting membrane + endothelium also depended on the species, varying from highly negative for rabbits to highly positive for pigs.

No significant differences were found between the right and left eyes. Ribeiro et al. (16) showed that ocular measurements in the right and left eyes were not significantly different, and the same result was obtained with males and females of adult goats. Studies have demonstrated a dependence of the morphological structure of the corneal parameters on animal species $(11,13,14)$, the habitat of the species $(2,12,14)$ and environmental conditions of animals (14). Strom et al. (20) studied 133 young healthy intact laboratory beagles and discovered that, in all dogs, CCT increased 
with increasing age and body weight. This means that the structure of the cornea is changeable, and in one period cells of one layer might grow at a greater rate than in another period.

The comparative morphological evaluation of corneal parameters demonstrated the dependence of the relation between the investigated parameters on animal species. The data obtained open up new possibilities for further investigation of pathological corneal changes in veterinary ophthalmology.

\section{References}

1. Ahn S. J., Hong H. K., Na Y. M., Park S. J., Ahn J., Oh J., Chung J. Y., Park K. H., Woo S. J.: Use of Rabbit Eyes in Pharmacokinetic Studies of Intraocular Drugs. J. Vis. Exp. 2016 Jul 23, doi:10.3791/53878.

2. Almubrad T., Akthtar S.: Ultrastructure features of camel cornea - collagen fibril and proteoglycans. Veterinary ophthalmology 2012, 15, 36-41.

3. Andrew S. E.: Corneal diseases of rabbits. Vet. Clin. North Am Exot. Anim. Pract. 2002, 5, 341-356.

4. Ashby B. D., Qian G., Willcox M. D. P.: Corneal Injuries and Wound Healing - Review of Processes and Therapies. Austin J. Clin. Ophthalmol. 2014, 1 , 1017.

5. Broadwater J. J., Schorling J. J., Herring I. P., Pickett J. Ph.: Ophtalmic examination findings in adult pygmy goats (Capra hicus). Veterinary Ophthalmology 2007, 10, 269-273.

6. Brunettte I., Rosolen S. G., Carrier M.: Comparison of the pig and feline models for full thickness corneal transplantation. Veterinary Ophthalmology 2011, 14, 365-377.

7. Del Monte D. W., Kim T.: Anatomy and physiology of the cornea. J. Cataract Refract. Surg. 2011 Mar. 37, 588-598.

8. Guthoff R. F., Zhivov A., Stachs O.: In vivo confocal microscopy, an inner vision of the cornea - a major review. Clin. Exp. Ophthalmol. 2009 Jan., 37 , 100-117

9. Hayashi S., Osawa T., Tohyama K.: Comparative observations on corneas, with special reference to Bowman's layer and Descemet's membrane in mammals and amphibians. Journal of Morphology 2002, 247-258.
10. Kim D. H., Kim J., Jeong H., Lee H., Kim M. K., Wee W. R.: Biophysico functional compatibility of Seoul National University (SNU) miniature pig cornea as xenocorneal graft for the use of human clinical trial. Xenotransplantation 2016. Volume 23, Issue 3. 202-210.

11. Lai T., Tang Sh.: Cornea characterization using a combined multiphoton microscopy and optical coherence tomography system: Biomed Opt Express 2014 May. 1. 5, 1494-1511

12. Li J., Kuang K., Nielsen S., Fischbarg J.: Molecular identification and immunolocalization of the water channel protein aquaporin 1 in CBCECs. Investigative Ophthalmology and Visual Science 1999, 40, 1288-1292.

13. Meridano M. D., Costa J., Canals M.: A comparative study of Bowman's layer in some mammals: relationships with other constituent corneal structures. European Journal of anatomy 2002, 6, 133-139.

14. Nautschel N., Bauer A., Steff M., Amselguber W. M.: Comparative morphological evaluation of domestic animal cornea. Veterinary Ophthalmology 2016 19, 297-304.

15. Potter T. J., Hallowell G. D., Bowen I. M.: Ultrasonographic anatomy of the bovine eye. Vet. Radiol. Ultrasound 2008 Mar-Apr. 49, 172-177.

16. Ribeiro A. P., Santos N. L., Silva V. C., Campos A. F., de Almeida Teixeira I. A., Laus J. L.: Ultrasonographic and ecobiometric findings in the eyes of adult goats. Ciencia rural, Santa Maria 2010, 40, 568-573.

17. Rodriques-Ramos Fernandez J., Dubielzig R. R.: Ocular comparative anatomy of the family Rodentia. Veterinary Ophthalmology 2013, 16, 94-99.

18. Ruiz-Ederra J., Garcia M., Hermandez M.: The pig eye as a novel model of glaucoma. Experimental Eye Research 2005, 81, 561-569.

19. Sanchez I., Martin R., Ussa F., Fernandez-Bueno I.: The parameters of the porcine eyeball. Graefes Arch. Clin. Exp. Ophthalmol. 2011, 475-482.

20. Strom A. R.: In vivo evaluation of the cornea and conjunctiva of the normal laboratory beagle using time- and Fourier-domain optical coherence tomography and ultrasound pachymetry. Veterinary ophthalmology 2016, 19, 50-56.

21. Wang X., Dong J., Wu Q.: Mean central corneal thickness and corneal power measurements in pigmented and white rabbits using Visante optical coherence tomography and ATLAS corneal topography. Veterinary ophthalmology 2014, 17, 87-90.

Corresponding author: Assoc. Prof. Dr. Vida Babrauskienė, Department of Anatomy and Physiology, Faculty of Veterinary Medicine, Lithuanian University of Health Sciences, Kaunas, Tilžès 18, Kaunas, Lithuania; e-mail: vida.babrauskiene@Ismuni.It 